\title{
PENGARUH FAKTOR PANJANG KELERENGAN TERHADAP PENENTUAN AWAL EROSI LAHAN
}

\section{EFFECT OF LENGTH FACTOR SLOPE TO EARLY DETERMINATION OF LAND EROSION}

\author{
Teguh Marhendi*, Iskahar \\ Program Studi Teknik Sipil, Fakultas Teknik \\ Universitas Muhammadiyah Purwokerto \\ Jl. Raya Dukuh Waluh PO Box 202 Purwokerto 53182 \\ Telp (0281)636751 ext 130 \\ *E-mail: tmarhendi@gmail.com
}

Histori Artikel:

Submitted:

$30 / 05 / 2017$

Revised:

$12 / 07 / 2017$

Accepted:

$20 / 08 / 2017$

\section{ABSTRAK}

Salah satu faktor penentu dalam analisis erosi lahan adalah faktor panjang kelerengan lahan daerah aliran sungai. Perubahan panjang kelerengan, akan memberikan dampak terhadap besaran erosi lahan tersebut.

Penelitian ini dimaksudkan untuk mengkaji pengaruh panjang kelerengan lahan terhadap penentuan awal erosi lahan yang terjadi di Daerah Aliran Sungai Merawu. Kajian diawali dengan penyusunan peta jenis-jenis tanah sesuai dengan kondisi setempat dan tanaguna lahannya untuk menentukan panjang kelerengan lahan. Kajian selanjutnya adalah menentukan besaran erosi lahan dengan formula USLE. Analisis dilakukan menggunakan data peta satuan lahan dan tataguna lahan untuk menentukan faktor $\mathrm{C}$ dan $\mathrm{K}$, sedangkan data hujan menggunakan data tahun 1988 sampai dengan 2008.

Hasil analisis menunjukkan bahwa variasi kelerengan lahan memberikan pengaruh terhadap penentuan awal erosi lahan pada lokasi penelitian. Berubahnya satuan lahan dan kelerengan lahan akan memberikan perubahan tehadap besaran erosi lahan

Kata kunci: DAS Merawu, Karakteristik tanah, erosi lahan

\begin{abstract}
The soil characteristic is a determinan factor to erosion analysis. The changes of slope length was impact to amount of erosion.

The research aim to study influence of a slope length at erosion analysis. Pre- eliminary study was preparation the maps of soil kinds appropriate landuse to slope length analysis and then determination the amount of erosion by USLE formulation. The $\mathrm{C}$ and $\mathrm{K}$ factor was determination with soil maps and landuse and rainfall data at 1988 to 2008. The result of research shown that the slope length was influence to changes the amount of erosion
\end{abstract}

Keyword: Merawu Basin, The slope length, erosion 


\section{PENDAHULUAN}

Erosi merupakan proses penghanyutan tanah oleh desakan-desakan atau kekuatan air dan angin baik berlangsung secara alamiah (geological erosion) maupun akibat tindakan manusia (acceleration erosion). Sedangkan sedimentasi merupakan proses pengendapan butir-butir tanah akibat erosi pada tempattempat yang lebih rendah. Sedimen yang tererosi selanjutnya akan terpindahkan oleh aliran air melalui lereng DAS dan menuju sistem saluran. Sebagian massa sedimen akan terdeposisi (terendapkan) pada lereng DAS dan sebagian lain akan terangkut dan mengendap pada sistem saluran (Arsyad, S, 1989; Budiharjo, D., Syaifudin, 2001; Purbandono, dkk, 2006; Marhendi, T., 2013).
Salah satu faktor penentu terjadinya erosi adalah faktor kelerengan lahan. Pada lahan dengan kemiringan yang curam, kecenderungan terjadi erosi dan sedimentasi umumnya cukup besar. Dengan demikian, pada daerah/lahan yang memiliki kelerengan yang curam, proses erosi dan sedimen akan lebih mudah dibandingkan dengan lahan dengan karakteristik tanah yang tidak mudah teriurai (Wischmeier, W. H. and Smith, D. D., 1978; Lu, H., et al, 2003; Marhendi, T., 2014).

Mengacu data hujan bulanan Tahun 1988 sampai dengan 2008 (disajikan pada Gambar 1), kejadian hujan di DAS Merawu selalu berubah setiap tahun.

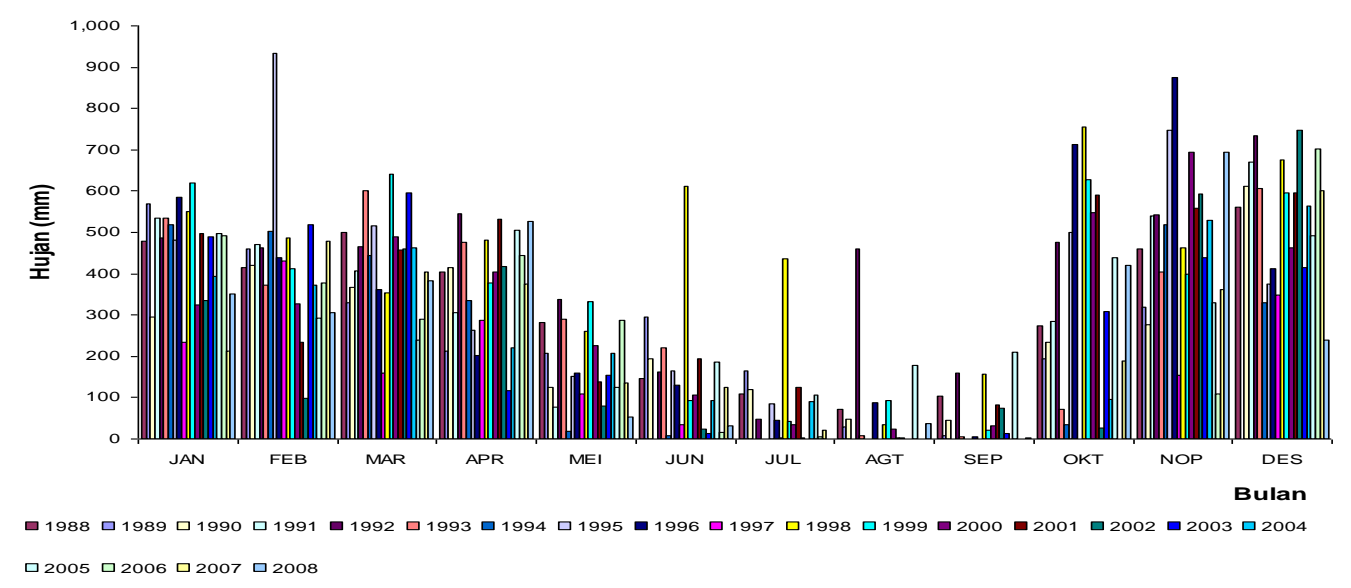

Gambar 1. Hujan bulanan DAS Merawu (Sumber: Analisis dari PT Indonesia Power, 2008, Marhendi, T., 2013)

\section{BAHAN DAN METODOLOGI}

Metode yang digunakan pada tulisan ini adalah dengan mengkaji data sekunder meliputi data hujan dan data-data peta satuan lahan, tataguna lahan dan kemiringan lahan. Kajian diawali dengan penyusunan peta satuan lahan. Kajian selanjutnya adalah menentukan besaran erosi lahan.

\section{Lokasi Penelitian}

Lokasi penelitian ini mengambil lokasi di Daerah Aliran Sungai Merawu yang terletak di wilayah Kabupaten Banjarnegara, Jawa Tengah, sebagaimana disajikan pada Gambar 2.

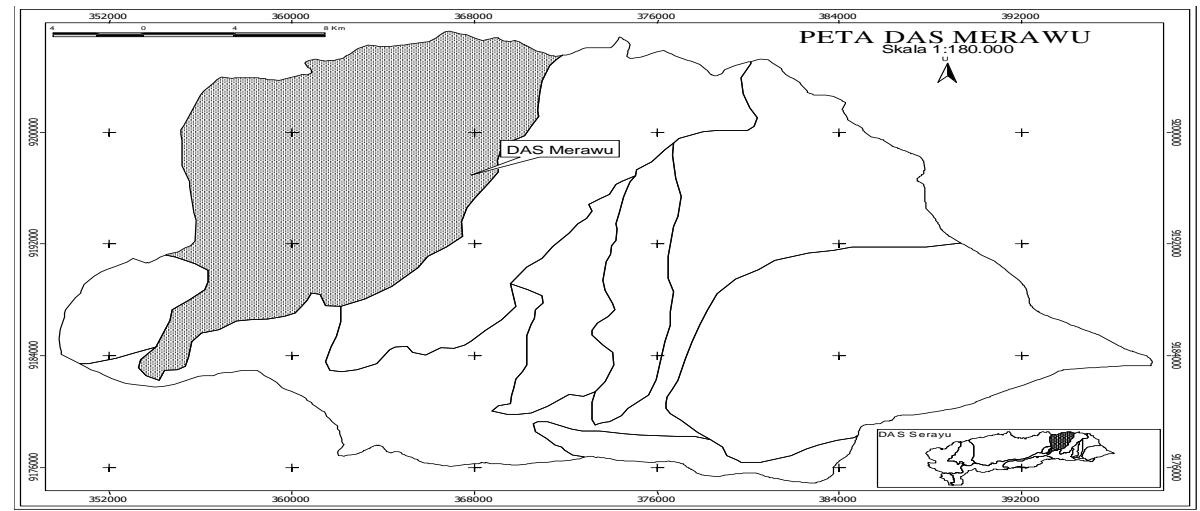

Gambar 2. Peta lokasi DAS Merawu (Marhendi, T., 2013) 


\section{Data}

Data yang digunakan dalam penelitian meliputi adalah data hujan tahun 1988 sampai dengan tahun 2008. Data lain yang digunakan berupa peta satuan lahan, landuse, kelerengan dan peta DAS Merawu.

\section{Metodologi Penelitian a. Analisis Erosi}

Dalam penelitian ini analisis erosi dilakukan menggunakan bantuan Arc-View GIS 3.3 yang meliputi overlay kelerengan, panjang kelerengan, jenis tanah, landuse. Selanjutnya berdasarkan hasil overlay tersebut dilakukan analisis erosi menggunakan Formula USLE (Wischmeier, W. H. and Smith, D, 1978).

$$
E=f(C, T, V, S, H)
$$

dengan,

$$
\begin{array}{ll}
E & =\text { erosi } \\
f & =\text { faktor yang mempengaruhi erosi } \\
C & =\text { klimatologi (iklim) } \\
T & =\text { topografi } \\
V & =\text { vegetasi } \\
S & =\text { karakteristik tanah } \\
H & =\text { kegiatan manusia }
\end{array}
$$

Formula USLE digunakan untuk memperkirakan laju erosi tanah yang berasal dari erosi permukaan dan erosi alur. Di luar kedua proses erosi tersebut belum terjangkau perhitungan laju erosinya. Sumber erosi di luar erosi permukaan dan erosi alur diantaranya erosi tebing dan longsoran. Kedua sumber erosi terakhir ini belum tercakup dalam perhitungan formulasi USLE.

Mengacu penelitian Purbandono, dkk (2006), pada sebuah DAS, laju erosi tahunan pada umumnya dimodelkan secara empirik dengan Universal Soil Loss Equation (USLE), yang dirumuskan sebagai berikut.

$$
E=L_{S} C K R
$$

dengan,

$E$ = laju erosi (ton $/ \mathrm{km}^{2} /$ tahun),

$L_{S}=$ indeks kemiringan lereng,

$C=$ tutupan lahan,

$K=$ erodibilitas dan,

$R=$ erosivitas.

\section{b. Indeks Kemiringan Lahan (Ls)}

Secara empirik, persamaan laju erosi yang ditunjukkan pada persamaan (2) dinyatakan dalam ton/km2/tahun. Mengacu Lu, H., et al, (2003) dan Purbandono, dkk (2006), LS dapat diperoleh menggunakan Model Elevasi Digital (DEM) untuk daerah yang diteliti.
Formula USLE pertama kali dikembangkan di USDA-SCS ( United State Departmen of Agriculture- Soil Conservation Service) bekerjasama dengan Universitas Purdue (Williams and Berndt, 1972, dalam Lu, H., et al, 2006). Pada penggunaan formula USLE, terjadinya erosi selalu dikaitkan dengan lima faktor penyebab yaitu faktor iklim, faktor tanah, topografi, faktor tutupan lahan dan faktor kegiatan atau perilaku manusia. Oleh karena itu formula ini memperhitungkan kelima faktor tersebut dalam menentukan metode pendugaan besar erosi suatu lahan. Dalam rumus USLE disebutkan :

$L_{S}=\left(\frac{L}{k}\right)^{m}\left(k_{1} \sin ^{2} s+k_{2} \sin s+k_{3}\right)$

dengan,

$m=$ indeks kemiringan dengan ketentuan.

$$
\begin{aligned}
& m=0.2 \text { untuk } 0 \leq s<1 \\
& m=0.3 \text { untuk } 1 \leq s<3 \\
& m=0.4 \text { untuk } 3 \leq s<4.5 \\
& m=0.5 \text { untuk } s \geq 4.5
\end{aligned}
$$

$L=$ panjang profil kemiringan yang memiliki nilai lebih besar dari 122 m (Renard et al., 1997).

$s=$ persen kemiringan.

$k$, $k_{1}, k_{2}$ dan $k_{3}$ adalah konstanta-konstanta empirik dengan ketentuan, $k=22.1, k_{1}=65.41$, $k_{2}=4.56, k_{3}=0.065$.

Komponen $C$ pada formula ini menunjukkan pengaruh vegetasi, seresah, keadaan permukaan tanah dan pengelolaan lahan terhadap besarnya tanah yang tererosi (Purbandono, dkk, 2006).

Komponen $K$ menunjukkan nilai resistensi partikel sedimen terhadap energi kinetik yang ditimbulkan hujan dan pengangkutan oleh air limpasan permukaan yang dinilai sebagai erodibilitas (Purbandono, dkk, 2006).

$K=\frac{\left[2.1 \times 10^{-4}(12-O M) M^{1.14}+3.25(s-2)+2.5(p-3)\right] \ldots .}{100}$

Sementara itu, nilai R (erosivitas) dapat ditentukan dengan persamaan sebagai berikut:

$$
E I_{30}=\frac{\left(E * I_{30}\right)}{100}
$$

Selanjutnya telah diadakan pendekatan dalam menghitung $\mathrm{EI}_{30}$ dengan menggunakan data hujan harian, hari hujan dan hujan bulanan. Formulasi ini masih terbatas bagi daerah Pulau Jawa dan Pulau Madura. 
a) $R_{d}=\frac{2,467 *\left(P_{d}\right)^{2}}{0,02727 * P_{d}+0,275}$

dengan

$R_{d}=$ erosivitas hujan harian.

$P_{d}=\quad$ curah hujan harian dalam $\mathrm{cm}$.

b) $R_{m}=6,119 *\left(P_{m}\right)^{1,21} *(H H)^{-0,47} *\left(P_{\max }\right)^{0,53} \ldots(7)$ dengan,

$R_{m} \quad=$ erosivitas hujan bulanan.

$P_{m} \quad=$ hujan bulanan dalam $\mathrm{cm}$.

$H H=$ hari hujan dalam satu bulan.

$P_{\max }=$ hujan harian maximum pada bulan yang bersangkutan dalam $\mathrm{cm}$.

\section{Hasil dan Pembahasan}

Untuk menentukan erosi lahan menggunakan formula USLE, perlu dianalisis terlebih dahulu jenis-jenis satuan lahan serta data unit lahan. Data ini diperlukan untuk
Apabila hujan harian maximum pada bulanan yang akan dihitung erosivitasnya tidak ada, maka dapat digunakan formulasi sebagai berikut (Purbandono, 2006):

c) $R_{m}=2,21 * P_{m}^{1,36}$

dengan,

$P_{m}=$ curah hujan bulanan.

\section{c. Analisis Pengaruh Kelerengan lahan terhadap erosi lahan}

Berdasarkan tinjauan terhadap karakteristik tanah, selanjutnya dilakukan analisis pengaruh yang terjadi terhadap perubahan erosi melalui grafik.

menentukan kategori faktor $\mathrm{C}$ dan $\mathrm{K}$ dalam analisis erosinya. Dibawah ini disajikan tabel penentuan nilai $\mathrm{C}$ dan $\mathrm{K}$ dengan memperhatikan unit lahan, serta panjang kelerengan lahan.

Tabel 1. Penentuan nilai C dan K berdasarkan unit lahan dan tataguna lahan DAS Merawu

\begin{tabular}{|c|l|l|r|r|r|r|}
\hline Unit Lahan & $\begin{array}{c}\text { jenis } \\
\text { tanah }\end{array}$ & Guna lahan & luas (ha) & \multicolumn{1}{c|}{ \% luas } & \multicolumn{1}{c|}{ Nilai C } & Nilai K \\
\hline I & latosol & perkebunan & 13,9680 & 0,0300 & 0,1000 & 0,23 \\
\hline I & latosol & Sawah & 451,0730 & 0,9700 & 0,0100 & 0,23 \\
\hline IIA & latosol & Belukar & 234,3580 & 0,3359 & 0,0030 & 0,23 \\
\hline IIA & Andosol & Hutan & 283,0490 & 0,4057 & 0,0020 & 0,26 \\
\hline IIA & Andosol & Belukar & 180,2660 & 0,2584 & 0,0030 & 0,26 \\
\hline IIA & Andosol & Belukar & 458,7700 & 0,6576 & 0,0030 & 0,26 \\
\hline IIA & Andosol & Sawah & 259,6820 & 0,3722 & 0,0100 & 0,26 \\
\hline IIA & latosol & Belukar & 580,5440 & 0,8321 & 0,0030 & 0,31 \\
\hline IIB & Grumusol & perkebunan & 151,9030 & 0,3296 & 0,1000 & 0,26 \\
\hline IIB & latosol & perkebunan & 128,3390 & 0,2785 & 0,1000 & 0,23 \\
\hline IIB & latosol & perkebunan & 118,7600 & 0,2577 & 0,1000 & 0,23 \\
\hline IIB & latosol & Sawah & 61,8810 & 0,1343 & 0,0100 & 0,23 \\
\hline III & Latosol & hutan & 340,2410 & 0,0194 & 0,0020 & 0,23 \\
\hline III & Latosol & hutan & 70,0030 & 0,0040 & 0,0020 & 0,23 \\
\hline III & Latosol & Belukar & 179,5260 & 0,0102 & 0,0030 & 0,23 \\
\hline III & Latosol & Belukar & 246,0440 & 0,0140 & 0,0030 & 0,23 \\
\hline III & Latosol & Belukar & 138,4450 & 0,0079 & 0,0030 & 0,23 \\
\hline III & Latosol & Belukar & 979,5690 & 0,0559 & 0,0030 & 0,23 \\
\hline III & Andosol & tegal & 482,9480 & 0,0276 & 0,0050 & 0,26 \\
\hline III & Andosol & Belukar & 6138,2190 & 0,3502 & 0,0030 & 0,26 \\
\hline III & Andosol & sawah & 110,3380 & 0,0063 & 0,0100 & 0,26 \\
\hline III & Grumusol & Belukar & 25,3140 & 0,0014 & 0,0030 & 0,26 \\
\hline III & Grumusol & Belukar & 159,3670 & 0,0091 & 0,0030 & 0,26 \\
\hline III & Grumusol & Belukar & 50,0120 & 0,0029 & 0,0030 & 0,26 \\
\hline III & Grumusol & Belukar & 1041,7070 & 0,0594 & 0,0030 & 0,26 \\
\hline III & Grumusol & Perkebunan & 1103,4690 & 0,0630 & 0,1000 & 0,26 \\
\hline III & Grumusol & sawah & 192,7840 & 0,0110 & 0,0100 & 0,26 \\
\hline III & Grumusol & hutan & 274,4980 & 0,0157 & 0,0020 & 0,26 \\
\hline III & Grumusol & hutan & 116,0880 & 0,0066 & 0,0020 & 0,26 \\
\hline
\end{tabular}


Teguh Marhendi, Iskahar

Pengaruh Faktor Panjang Kelerengan Terhadap Penentuan Awal Erosi Lahan

\begin{tabular}{|c|c|c|c|c|c|c|}
\hline III & Grumusol & sawah & 89,5300 & 0,0051 & 0,0100 & 0,26 \\
\hline III & Grumusol & hutan & 28,5550 & 0,0016 & 0,0020 & 0,26 \\
\hline III & Grumusol & hutan & 50,2580 & 0,0029 & 0,0020 & 0,26 \\
\hline III & Latosol & hutan & 192,7880 & 0,0110 & 0,0020 & 0,31 \\
\hline III & Latosol & sawah & 65,0580 & 0,0037 & 0,0100 & 0,31 \\
\hline III & Latosol & sawah & 25,3420 & 0,0014 & 0,0100 & 0,31 \\
\hline III & Regosol & Belukar & 100,0610 & 0,0057 & 0,0030 & 0,31 \\
\hline III & Latosol & Perkebunan & 265,4110 & 0,0151 & 0,1000 & 0,23 \\
\hline III & Latosol & Perkebunan & 359,6780 & 0,0205 & 0,1000 & 0,23 \\
\hline III & Latosol & sawah & 404,3030 & 0,0231 & 0,0100 & 0,23 \\
\hline III & Latosol & Belukar & 93,1840 & 0,0053 & 0,0030 & 0,23 \\
\hline III & Latosol & Belukar & 221,3910 & 0,0126 & 0,0030 & 0,23 \\
\hline III & Latosol & hutan & 105,3390 & 0,0060 & 0,0010 & 0,23 \\
\hline III & litosol & Perkebunan & 84,4210 & 0,0048 & 0,1000 & 0,31 \\
\hline III & litosol & hutan & 52,4150 & 0,0030 & 0,0020 & 0,31 \\
\hline III & Latosol & Belukar & 3742,0310 & 0,2135 & 0,0030 & 0,23 \\
\hline IV & Grumusol & perkebunan & 220,5360 & 0,5269 & 0,1000 & 0,26 \\
\hline IV & Grumusol & hutan & 198,0310 & 0,4731 & 0,0020 & 0,26 \\
\hline VA & latosol & hutan & 548,9980 & 0,4558 & 0,0020 & 0,23 \\
\hline VA & Andosol & hutan & 372,1250 & 0,3090 & 0,0020 & 0,26 \\
\hline VA & Andosol & tegal & 283,2500 & 0,2352 & 0,0050 & 0,26 \\
\hline VB & latosol & hutan & 691,5030 & 0,8010 & 0,0020 & 0,23 \\
\hline VB & latosol & belukar & 36,8310 & 0,0427 & 0,0030 & 0,23 \\
\hline VB & latosol & belukar & 25,0550 & 0,0290 & 0,0030 & 0,23 \\
\hline VB & Andosol & hutan & 93,8270 & 0,1087 & 0,0020 & 0,26 \\
\hline VB & Andosol & belukar & 16,1070 & 0,0187 & 0,0030 & 0,26 \\
\hline VC & Grumusol & belukar & 157,2140 & 0,3625 & 0,0030 & 0,23 \\
\hline VC & Grumusol & belukar & 99,8930 & 0,2304 & 0,0030 & 0,23 \\
\hline VC & Grumusol & hutan & 176,5330 & 0,4071 & 0,0020 & 0,23 \\
\hline VD & Grumusol & hutan & 33,1340 & 0,2242 & 0,0020 & 0,23 \\
\hline VD & Litosol & hutan & 114,6570 & 0,7758 & 0,0020 & 0,23 \\
\hline
\end{tabular}

Sumber: Analisis, 2017 (Mengacu Marhendi, T., 2014)

Tabel 2. Panjang Kelerengan Unit lahan VB di DAS Merawu

\begin{tabular}{|r|c|c|c|c|c|c|c|c|c|c|}
\hline No & $\mathbf{L}$ & $\mathbf{K}$ & $\mathbf{m}$ & $\mathbf{k}_{\mathbf{1}}$ & $\mathbf{s}$ & $\mathbf{s} \%$ & $\mathbf{s} \% \mathbf{~ r a d}$ & $\mathbf{k}_{\mathbf{2}}$ & $\mathbf{k}_{\mathbf{3}}$ & $\mathbf{L}_{\mathbf{s}}$ \\
\hline 1 & 262,5000 & 22,1000 & 0,2000 & 65,4100 & 0,0000 & 0,0000 & 0,0000 & 4,5600 & 0,0650 & 0,1066 \\
\hline 2 & 1032,1865 & 22,1000 & 0,5000 & 65,4100 & 0,5537 & 55,3710 & 0,9664 & 4,5600 & 0,0650 & 328,7556 \\
\hline 3 & 234,5000 & 22,1000 & 0,2000 & 65,4100 & 0,0000 & 0,0000 & 0,0000 & 4,5600 & 0,0650 & 0,1042 \\
\hline 4 & 644,0497 & 22,1000 & 0,5000 & 65,4100 & 0,4828 & 48,2759 & 0,8426 & 4,5600 & 0,0650 & 215,4226 \\
\hline \multicolumn{8}{c|}{ Sumber: analisis, 017 (Mengacu Marhendi, T., 2014) }
\end{tabular}

Tabel 3 Panjang Kelerengan Unit Lahan VC di DAS Merawu

\begin{tabular}{|r|c|c|c|c|c|c|c|r|r|r|}
\hline No & $\mathbf{L}$ & $\mathbf{K}$ & $\mathbf{m}$ & $\mathbf{k}$ 1 & $\mathbf{s}$ & $\mathbf{s \%}$ & $\mathbf{s \% ~ r a d}$ & $\mathbf{k}_{\mathbf{2}}$ & \multicolumn{1}{|c|}{$\mathbf{k}_{\mathbf{3}}$} & $\mathbf{L}_{\mathbf{s}}$ \\
\hline 1 & 428,5714 & 22,1000 & 0,2000 & 65,4100 & 0,0000 & 0,0000 & 0,0000 & 4,5600 & 0,0650 & 0,1176 \\
\hline 2 & 174,8659 & 22,1000 & 0,5000 & 65,4100 & 0,2012 & 20,1250 & 0,3512 & 4,5600 & 0,0650 & 26,3779 \\
\hline 3 & 134,9558 & 22,1000 & 0,5000 & 65,4100 & 0,5146 & 51,4583 & 0,8981 & 4,5600 & 0,0650 & 107,8591 \\
\hline 4 & 53,3300 & 22,1000 & 0,2000 & 65,4100 & 0,0000 & 0,0000 & 0,0000 & 4,5600 & 0,0650 & 0,0775 \\
\hline 5 & 221,7922 & 22,1000 & 0,5000 & 65,4100 & 0,5035 & 50,3546 & 0,8789 & 4,5600 & 0,0650 & 134,1895 \\
\hline 6 & 218,8255 & 22,1000 & 0,5000 & 65,4100 & 0,3648 & 36,4837 & 0,6368 & 4,5600 & 0,0650 & 81,5038 \\
\hline
\end{tabular}

Sumber: analisis, 2014 
Tabel 4 Panjang Kelerengan Unit Lahan VD di DAS Merawu

\begin{tabular}{|r|c|c|c|c|c|c|c|c|c|r|}
\hline No & $\mathbf{L}$ & $\mathbf{K}$ & $\mathbf{m}$ & $\mathbf{k}_{\mathbf{1}}$ & $\mathbf{s}$ & $\mathbf{s \%}$ & $\mathbf{s \% ~ r a d}$ & $\mathbf{k}_{\mathbf{2}}$ & $\mathbf{k}_{\mathbf{3}}$ & $\mathbf{L}_{\mathbf{s}}$ \\
\hline 1 & 315,5163 & 22,1000 & 0,5000 & 65,4100 & 0,5084 & 50,8444 & 0,8874 & 4,5600 & 0,0650 & 162,2166 \\
\hline 2 & 258,2736 & 22,1000 & 0,5000 & 65,4100 & 0,3601 & 36,0082 & 0,6285 & 4,5600 & 0,0650 & 86,6721 \\
\hline 3 & 301,7590 & 22,1000 & 0,4000 & 65,4100 & 0,0415 & 4,1459 & 0,0724 & 4,5600 & 0,0650 & 2,0956 \\
\hline 4 & 231,9171 & 22,1000 & 0,5000 & 65,4100 & 0,4779 & 47,7897 & 0,8341 & 4,5600 & 0,0650 & 127,3985 \\
\hline 5 & 297,2356 & 22,1000 & 0,5000 & 65,4100 & 0,1706 & 17,0648 & 0,2978 & 4,5600 & 0,0650 & 25,8034 \\
\hline \multicolumn{8}{|c|}{ Sumber: analisis, 017 Mengacu Marhendi, T., 2014) }
\end{tabular}

Tabel 5. Erosi lahan bulanan DAS Merawu berdasar Unit lahan

\begin{tabular}{|c|c|c|c|c|c|c|c|c|c|c|c|c|}
\hline \multirow{2}{*}{$\begin{array}{c}\text { Unit } \\
\text { Lahan }\end{array}$} & \multicolumn{12}{|c|}{ Bulan } \\
\hline & Jan & Feb & Mar & Apr & Mei & Jun & Jul & Ags & Sep & Okt & Nov & Des \\
\hline I & 0,8064 & 0,6168 & 0,5363 & 0,4190 & 0,1993 & 0,1021 & 0,0503 & 0,0435 & 0,0977 & 0,3294 & 0,5822 & 0,7444 \\
\hline IIA & 7,9621 & 6,0900 & 5,2948 & 4,1371 & 1,9680 & 1,0083 & 0,4969 & 0,4294 & 0,9648 & 3,2521 & 5,7478 & 7,3494 \\
\hline IIB & 49,3390 & 37,7378 & 32,8107 & 25,6367 & 12,1953 & 6,2485 & 3,0788 & 2,6611 & 5,9788 & 20,1522 & 35,6175 & 45,5425 \\
\hline III & 10,0111 & 7,6572 & 6,6574 & 5,2018 & 2,4745 & 1,2678 & 0,6247 & 0,5400 & 1,2131 & 4,0890 & 7,2270 & 9,2408 \\
\hline IV & 164,4222 & 125,7611 & 109,3414 & 85,4343 & 40,6408 & 20,8230 & 10,2602 & 8,8681 & 19,9243 & 67,1572 & 118,6954 & 151,7702 \\
\hline VA & 11,7891 & 9,0171 & 7,8398 & 6,1256 & 2,9140 & 1,4930 & 0,7357 & 0,6358 & 1,4286 & 4,8152 & 8,5105 & 10,8819 \\
\hline VB & 11,1689 & 8,5427 & 7,4274 & 5,8034 & 2,7607 & 1,4145 & 0,6970 & 0,6024 & 1,3534 & 4,5619 & 8,0628 & 10,3095 \\
\hline VC & 23,0368 & 17,6201 & 15,3196 & 11,9700 & 5,6941 & 2,9175 & 1,4375 & 1,2425 & 2,7916 & 9,4092 & 16,6301 & 21,2642 \\
\hline VD & 18,1926 & 13,9149 & 12,0982 & 9,4529 & 4,4967 & 2,3040 & 1,1353 & 0,9812 & 2,2045 & 7,4307 & 13,1331 & 16,7927 \\
\hline
\end{tabular}
Sumber: analisis, 2017 (Mengacu Marhendi, T., 2014)

Tabel 6. Rerata Erosi lahan bulanan DAS Merawu berdasar Unit lahan

\begin{tabular}{|c|c|c|c|c|c|c|c|c|c|c|c|c|}
\hline $\begin{array}{c}\text { Unit } \\
\text { Lahan }\end{array}$ & Jan & Feb & Mar & Apr & Mei & Jun & Jul & Ags & Sep & Okt & Nov & Des \\
\hline I & 0,4032 & 0,3084 & 0,2681 & 0,2095 & 0,0997 & 0,0511 & 0,0252 & 0,0217 & 0,0489 & 0,1647 & 0,2911 & 0,3722 \\
\hline IIA & 1,5924 & 1,2180 & 1,0590 & 0,8274 & 0,3936 & 0,2017 & 0,0994 & 0,0859 & 0,1930 & 0,6504 & 1,1496 & 1,4699 \\
\hline IIB & 16,4463 & 12,5793 & 10,9369 & 8,5456 & 4,0651 & 2,0828 & 1,0263 & 0,8870 & 1,9929 & 6,7174 & 11,8725 & 15,1808 \\
\hline III & 3,3370 & 2,5524 & 2,2191 & 1,7339 & 0,8248 & 0,4226 & 0,2082 & 0,1800 & 0,4044 & 1,3630 & 2,4090 & 3,0803 \\
\hline IV & 54,8074 & 41,9204 & 36,4471 & 28,4781 & 13,5469 & 6,9410 & 3,4201 & 2,9560 & 6,6414 & 22,3857 & 39,5651 & 50,5901 \\
\hline VA & 2,9473 & 2,2543 & 1,9599 & 1,5314 & 0,7285 & 0,3733 & 0,1839 & 0,1590 & 0,3571 & 1,2038 & 2,1276 & 2,7205 \\
\hline VB & 3,7230 & 2,8476 & 2,4758 & 1,9345 & 0,9202 & 0,4715 & 0,2323 & 0,2008 & 0,4511 & 1,5206 & 2,6876 & 3,4365 \\
\hline $\mathrm{VC}$ & 3,8395 & 2,9367 & 2,5533 & 1,9950 & 0,9490 & 0,4862 & 0,2396 & 0,2071 & 0,4653 & 1,5682 & 2,7717 & 3,5440 \\
\hline VD & 3,6385 & 2,7830 & 2,4196 & 1,8906 & 0,8993 & 0,4608 & 0,2271 & 0,1962 & 0,4409 & 1,4861 & 2,6266 & 3,3585 \\
\hline
\end{tabular}

Sumber: analisis, 2017 (Mengacu Marhendi, T., 2014) 


\section{Kesimpulan}

Hasil analisis menunjukkan bahwa panjang kelerengan lahan memberikan pengaruh terhadap penentuan awal erosi lahan yang terjadi di DAS Merawu.

\section{Ucapan Terimakasih}

Penulis mengucapkan terimakasih kepada PT Indonesia Power UBP Mrica yang telah meminjamkan data.

\section{DAFTAR PUSTAKA}

Arsyad, S, 1989, Konservasi Tanah dan Air, Penerbit, IPB, Bogor

Budiaharjo, D., Syaifudin, 2001, Erosi dan Sedimentasi di DPS Danau Beratan, Bali, Balai Sungai, Pusat Litbang Sumberdaya Air, Jl Solo-Kartosuro, KM 7 PO Box 159, Surakarta

Lu, H., et al, 2003, Modelling Sediment Delivery Ratio over the Murray
Darling Basin, CSIRO Land and Water, Canberra, Australia.

Purbandono, dkk, 2006, Evaluasi Perubahan Perilaku Erosi DASCitarum Hulu dengan Pemodelan Spasial, Jurnal Infrastruktur dan Lingkungan Binaan, Vol II No. 2, Bandung

Marhendi, T., 2013, Pengaruh Intensitas Hujan Terhadap Peningkatan Erosi Lahan Penelitian, 2011, LPPM UMP

Marhendi, T., 2014, Pengaruh Karakteristik Tanah Terhadap Perubahan Erosi Lahan Menggunakan Formula USLE, 2014, LPPM UMP

Wischmeier, W. H. and Smith, D. D., 1978, "Predicting Rainfall Erosion Losses - A Guide to Conservation Planning", US Dept. of Agricultural Handbook 537. 